\title{
Periorbital cellulits - a mistaken diagnosis!
}

\author{
Julia Fozard, ${ }^{1}$ Nikila Pandya, ${ }^{2}$ Ashok Pulikot, ${ }^{2}$ David Fish, ${ }^{3}$ Raman Malhotra, ${ }^{4}$ Damian Lake ${ }^{4}$ \\ 1Department of Paediatrics, Maidstone Hospital, Dagenham, UK; \\ 2Department of Paediatrics, Maidstone and Tunbridge Wells, Kent, UK; \\ ${ }^{3}$ Department of Pathology, Maidstone Hospital, Maidstone, Kent, UK; \\ ${ }^{4}$ Department of Ophthalmology, Queen Victoria Hospital, East Grinstead, UK \\ Correspondence to Dr Nikila Pandya, nikilapandya@nhs.net
}

\begin{abstract}
Summary
A 12-year-old girl presented with a 1 week history of orbital swelling associated with granuloma, purulent discharge from the eye and preauricular and submandibular lymphadenopathy. Initial conventional treatment for presumed preseptal cellulitis was unsuccessful. Despite treatment with broad spectrum antibiotics, the preseptal cellulitis progressed to orbital cellulitis with restriction of eye movements in addition to the marked conjunctival chemosis and haemorrhage. A detailed history revealed she had been in close contact with newborn kittens at home and biopsy of the granuloma demonstrated Bartonella species, confirming the diagnosis of cat scratch disease. The child received a course of appropriate oral and topical antibiotics and steroids. Unfortunately eyesight in the right eye remains poor on follow-up.
\end{abstract}

\section{BACKGROUND}

Parinaud's oculoglandular syndrome is a rare manifestation of cat scratch disease (CSD) characterised by unilateral conjunctivitis with polypoid granuloma and preauricular lymphadenopathy. Easily mistaken for periorbital cellulitis, this case illustrates the need for careful history taking in order to make prompt and correct diagnosis as there can be considerable damage to vision if left untreated.

\section{CASE PRESENTATION}

A 12-year-old healthy girl presented with a 1 week history of right-sided periorbital swelling, purulent discharge and pain in her jaw. There was no history of fever and the child was otherwise clinically well. On physical examination, a right swollen eyelid with a granuloma alongside a purulent discharging right eye was evident. A large, firm, $3 \mathrm{~cm}$ by $2 \mathrm{~cm}$ jugulodigastric lymph node and a preauricular lymph node were palpable on the right (figure 1). The left eye was unaffected.

Initial working diagnosis was that of a preseptal cellulitis. The rest of physical examination was unremarkable. Despite conventional broad spectrum antibiotics, intravenous co-amoxiclav and metronidazole, this progressed to orbital cellulitis with reduced eye movements and chemosis with a haemorrhagic conjunctiva (figure 2). A more detailed history revealed a home full of pets including new born kittens which she had been cuddling and playing with. There was no recollection of a scratch or licking near the eye but she admitted that the kittens were cuddled close to the face.

\section{INVESTIGATIONS}

Full blood count and $\mathrm{C}$ reactive protein was normal, however ESR was raised at $45 \mathrm{~mm} / \mathrm{h}$.

Initial CT scan of her orbits revealed a preseptal cellulitis.

Bartonella serology was negative for Bartonella henselae and Bartonella quintana and therefore unfortunately no PCR was sent. A biopsy of her granulomatous lesion on the right eyelid was taken and sent for histology. Haematoxylin and eosin staining showed clusters of organisms that resembled Bartonella species (figure 3). A further biopsy of her cornea revealed a keratitic change consistent with CSD.

\section{DIFFERENTIAL DIAGNOSIS}

Although bartonella serology was negative, on the basis of contact history, with probable self-inoculation, along with the positive identification of Bartonella on biopsy, the diagnosis was clinically confirmed as the unusual manifestation of CSD, Parinaud's oculoglandular syndrome.

\section{TREATMENT}

She received intravenous co-amoxiclav and metronidazole initially for the first 3 days, which was then changed to intravenous tazocin and clindamycin on advice from microbiology. Methylprednisolone was added for 2 days which was followed by tapering prednisolone over 6 weeks. She was also treated topically with chloramphenicol eye drops, which was later changed to levofloxacillin drops and finally dexamethasone eye drops.

\section{OUTCOME AND FOLLOW-UP}

Unfortunately, vision in her right eye remains poor.

\section{DISCUSSION}

Cat-scratch disease is an infection caused by $B$ henselae, a fastidious gram-negative bacillus acquired from exposure to an infected kitten or cat and was first described by Debre in $1950 .{ }^{1}$ It particularly affects children and young adults.

Head and neck lymph node enlargement are considered as the most common clinical presentation of CSD alongside skin lesions close to the site of inoculation, appearing 2 to 3 weeks after contact with the cat.

Atypical presentation is seen in up to $25 \%$ of cases, and manifests itself as ocular involvement, encephalopathy, 


\section{BMJ Case Reports}

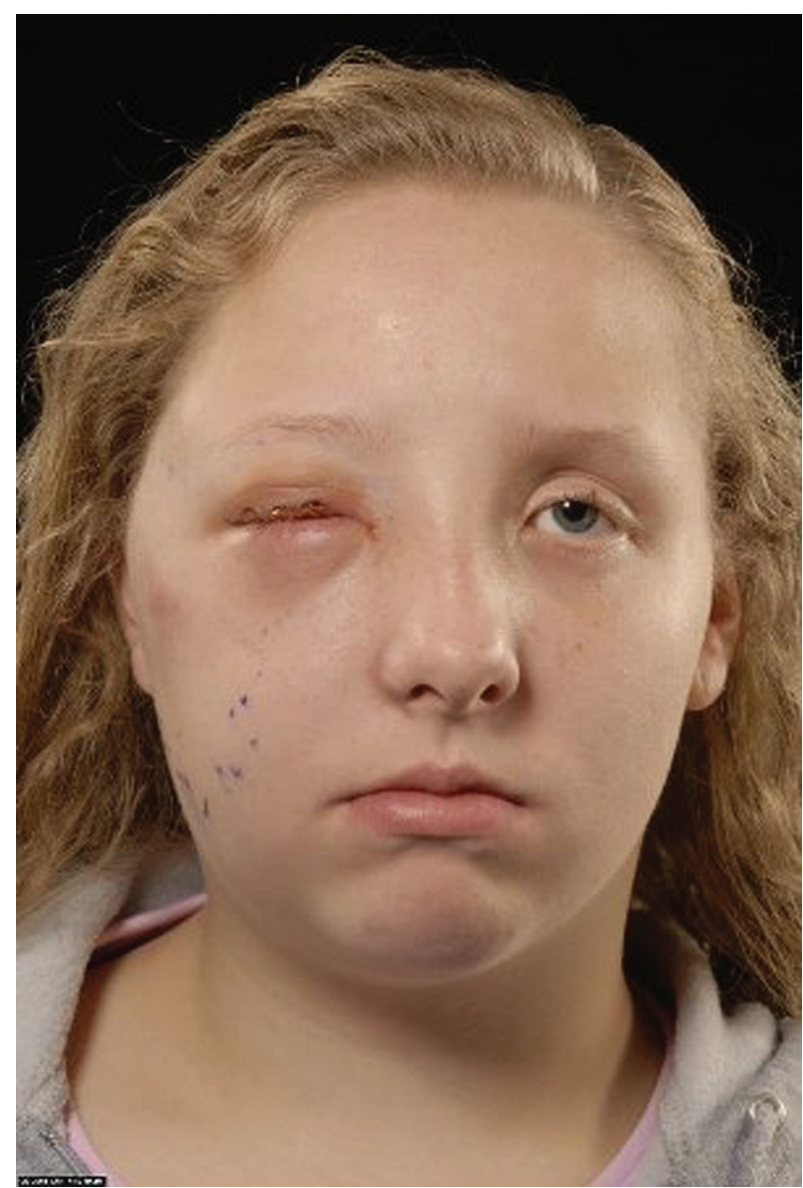

Figure 1 Periorbital swelling, purulent granulomatous conjunctivitis, preauricular swelling of lymph gland, lymph node at angle of jaw.

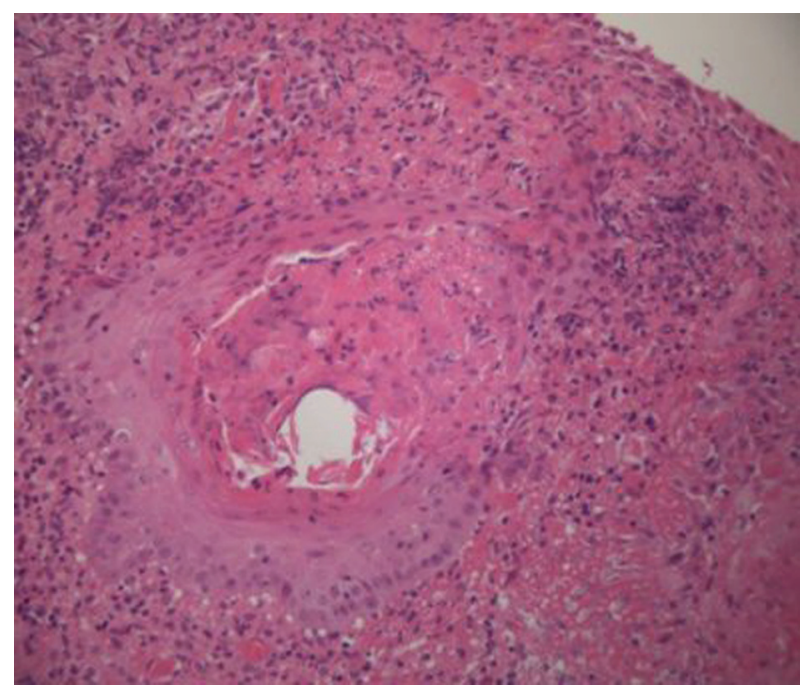

Figure 3 H\&E stain showing Bartonella.

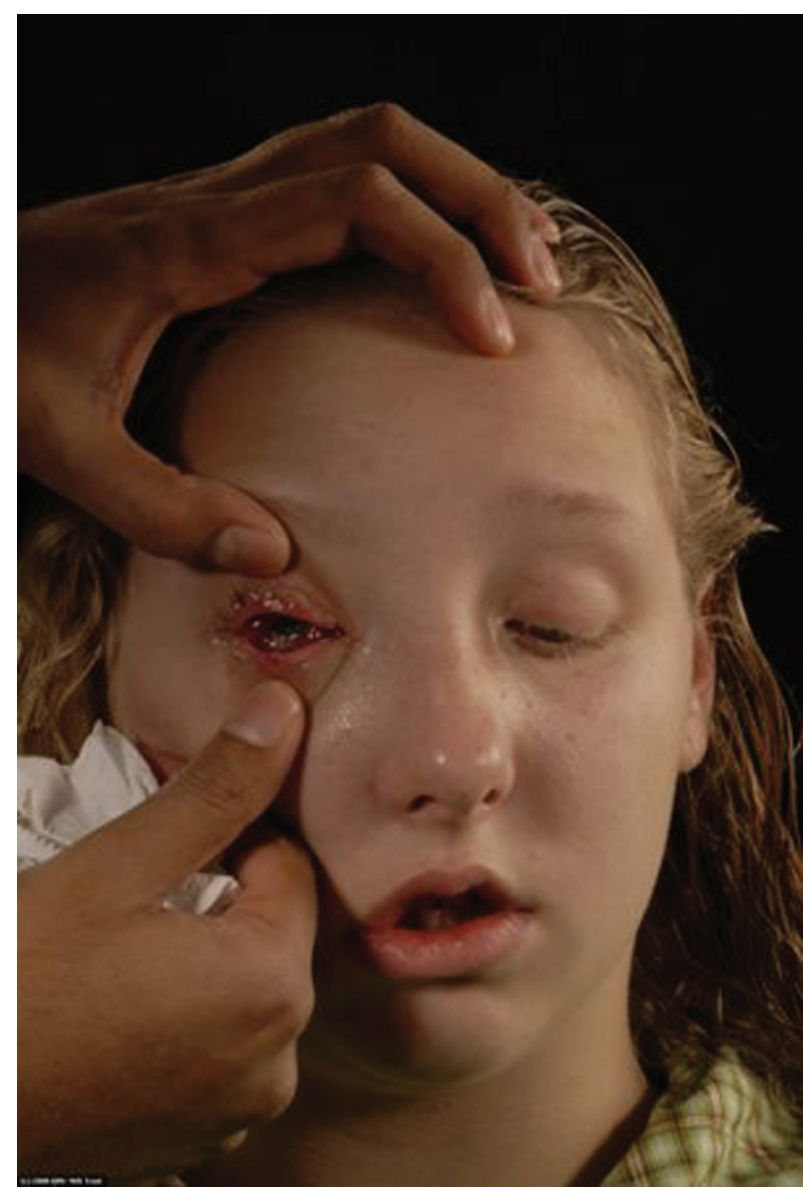

Figure 2 Marked conjunctival chemosis and haemorrhage of conjunctiva.

granulomatous hepatitis, hepatosplenic infection, endocarditis and osteomyelitis. Parinaud oculoglandular syndrome, an unusual ocular manifestation of this disease seen in $2 \%$ of cases, is characterised by unilateral conjunctivitis with polypoid granuloma, usually of the palpebral conjunctiva, and preauricular lymphadenopathy. Inoculation is usually by hand-eye transmission rather than direct scratch to the eye. ${ }^{2}$ The diagnosis is supported by a history of exposure to cats and is confirmed by positive serologic tests or positive PCR assay. ${ }^{3}$

Azithromycin therapy is associated with more rapid diminution in size of infected lymph nodes however cases of CSD occurring in immunocompetent hosts do not require anti-infective therapy for resolution of infection. ${ }^{4}$ In complicated CSD, treatment with trimethoprim-sulphamethoxazole, ciprofloxacin or azithromycin is recommended, with gentamicin being reserved for the severely ill patient. 5

Diagnosis is based on history, serology and histological findings, ${ }^{6}$ in particular four criteria: exposure to a cat, usually an immature one; the presence of a localised granuloma of the eye; the presence of preauricular lymphad- 


\section{BMJ Case Reports}

enopathy; and a positive skin test to cat-scratch antigen of known potency.

\section{Learning points}

- Granulomatous conjunctivitis of the eye should always arouse suspicion of possible CSD and careful history taking is essential.

- In cases of unresolving preseptal cellulitis associated with lymphadenopathy - further investigations may be warranted.

- Most cases of CSD are self-limiting but in cases of ocular involvement, prompt recognition and treatment is essential in order to preserve long-term function of the eye.
Competing interests None.

Patient consent Obtained.

\section{REFERENCES}

1. Debre R, Lamy M, Jammet M.L., et al. La Maladie des griffes de chat. Sem Hop Paris. 1950;26:1895-1901.

2. Carithers HA. Cat-scratch disease. An overview based on a study of 1,200 patients. Am J Dis Child 1985;139:1124-33.

3. Shoham N, Miron D, Raz R, et al. Familial Parinaud oculoglandular syndrome in cat scratch disease. Harefuah 2000;138:1034-6.

4. Conrad DA. Treatment of cat-scratch disease. Curr Opin Pediatr 2001;13:56-9.

5. Windsor JJ. Cat-scratch disease: epidemiology, aetiology and treatment. $\mathrm{Br}$ J Biomed Sci 2001;58:101-10.

6. Rombaux $\mathbf{P}, M^{\prime} B i l o$ T, Badr-el-Din A, et al. Cervical lymphadenitis and cat scratch disease (CSD): an overlooked disease? Acta Otorhinolaryngol Belg 2000;54:491-6.

7. Marqileth AM. Dermatologic manifestations and update of cat scratch disease. Paediatric Dermatology 1988;5:1-9.

This pdf has been created automatically from the final edited text and images.

Copyright 2011 BMJ Publishing Group. All rights reserved. For permission to reuse any of this content visit http://group.bmj.com/group/rights-licensing/permissions.

BMJ Case Report Fellows may re-use this article for personal use and teaching without any further permission.

Please cite this article as follows (you will need to access the article online to obtain the date of publication).

Fozard J, Pandya N, Pulikot A, Fish D, Malhotra R, Lake D. Periorbital cellulits - a mistaken diagnosis!. BMJ Case Reports 2011;10.1136/bcr.07.2011.4508, date of publication

Become a Fellow of BMJ Case Reports today and you can:

- Submit as many cases as you like

- Enjoy fast sympathetic peer review and rapid publication of accepted articles

- Access all the published articles

- Re-use any of the published material for personal use and teaching without further permission

For information on Institutional Fellowships contact consortiasales@bmjgroup.com

Visit casereports.bmj.com for more articles like this and to become a Fellow 